\title{
Web - Based Intelligent Inventory Management System
}

\author{
Madamidola O. A \\ Department of Computer Science \\ Federal University of Technology \\ Akure
}

Daramola O.A

Department of Computer Science

Federal University of Technology

Akure

\author{
Akintola K .G. \\ Department of Computer Science \\ Federal University of Technology \\ Akure
}

\section{ABSTRACT}

All around the world, inventory managers are faced with the complexities of simultaneously striving to retain constant manufacturing operation, render quality and adequate services to customer and keep goods at optimum level as well as having proper inventory management policy in place. As company grows a number of problem also arises first, a varieties of item are needed to be maintained in the inventory making it difficult to for managers to keep track, therefore a formal record keeping will have to evolve, besides that as quantities in inventory grows more space is required to do business. Due to local and global competition any company that must survive in the competitive world must take an advantage of effective management of its inventory seriously therefore the use of intelligent approach for effective and efficient inventory management system has become indispensable. This work developed an intelligent system implemented in a web based environment to integrate multiple stores also providing an effective coordination of all of the stores, intelligently determining the different reorder points of all the disparate stores in the systems and communicating the information back to the centralized store using Java Remote Method Invocation (RMI) with a secure socket layer (SSL), implemented using My Structured Query Language (MySQL), Database Management System, Hypertext Markup Language (HTML), JavaScript, Hypertext Preprocessor (PHP) and Xampp (Apache). The work optimized the performance of inventory management integrating multiple systems and providing an efficient coordination and monitoring moving away from single store into distributed system relating real time status of supplies at the different stores.

Keywords: Intelligence, Inventory Management, Fuzzy Logic, Information Extraction, Client -Server

\section{INTRODUCTION}

The control and maintenance of inventory is a problem experienced virtually by all business sectors. Inventories management is crucial for the sustainability and growth of any organization. Disregarding the necessity of inventory in any organization can lead to its shutting down, especially if the variables of productivity are poorly managed in progression to meet customers' need or desires. Inventory problem encompasses having adequate items available when desired by the customers and the stock of items must be in good condition, meaning that stock should not be too much or too little also, companies be positioned to meet customers' demands in term of quantity and quality. Considering improvement in customer satisfaction, the proficient management of inventories has become significant, because excess or shortage of inventories has remote effects on the supply chain cost therefore the need for inventory management has been articulated, it is observed that on one hand the need for sales and inventory management is growing while on the other the possibilities of artificial intelligence and software development being the fundamental part of inventory are also progressing. A major challenge is to ascertain the potential synergy between the 
business trend and artificial intelligence trend, the problem of an organization and the retailers can be taken as paradigm for instance, in order to sell an item, the retailer or manufacturer must sustain a stock of that item to meet the demand for it. Due to challenges that are associated with traditional inventories which range from theft, floods, loses in profit and frauds, it is difficult to maintain perfect inventory record thereby causing discrepancies in records. Although inventories over decades have which moved from manual systems to automated system, the efficiency and effectiveness of the system in cases where more than one store exist cannot be guaranteed, therefore there is a need to provide coordination and monitoring of all these stores in an intelligent manner that will increase productivity. The focus of this paper is to develop an intelligent inventory management system to coordinate stores of an organization, this is implemented in a web - based environment.

\section{RELATED WORKS}

Anigbogu et al. (2011) worked on an intelligent model for sales and inventory management. In their work, they focused on the mutual impacts of trends in inventory management and artificial intelligence after observing the need for emergence of inventory and intelligence, also the discrepancy between theory and practices of inventory, the workable approach presented still possess some restrictions because they are built on standalone systems which was not sufficient enough to capture the growing performance inventory optimization, also the database used has a limited space and cannot accommodate large data.

Chede et al. (2012) worked on Fuzzy Logic analysis based on Inventory Considering Demands and Stock Quantity on hand Their work was based on the principle of fuzzy knowledge bases two-stage tuning. According to this principle the construction of the "inputs - output" object model can be performed in two stages, which in analogy with classical methods, can be considered as stages of structural and parametrical identification. The result shows the fuzzy logic approach model gave the most appropriate result in term of inventory as they can get the value for any input in the system to optimize the inventory. The work was only proposed and not implemented.

Tanthatemee et al. (2012) worked on Fuzzy Inventory Control System for Uncertain Demand and Supply. In their work they propose a fuzzy logic control to treat the uncertainty regarding demand and supply in continuous inventory control system. MATLAB's fuzzy logic tool was used to represent the continuous inventory control system, the demand, supply, order and reorder points were described by linguistic terms with the main objectives to evaluate the order quantity and reorder point in each period taking into account the demand and supply uncertainties. . The result clearly shows that fuzzy logic control can extremely safe total inventory cost, moreover there was no shortage in any data set of tested data of the fuzzy logic control model which means that it provides customer satisfaction although demand and supply are uncertain. The work only handles uncertainties in supply and demands from a single store and not in multiple store

Loizidies (2013), worked on Development of SaaS Inventory Management System, he discovered the irregularities in the management of inventory of Caterpro Ltd which was associated with loss and inconsistencies in data recorded. His focus was to develop a Software as a Service web and more specifically an Inventory management system, to provide a basic tool for tracking as well as monitoring sales and inventory to individuals and small scale business who cannot afford the investment of a complete dedicated inventory management systems. The system was developed using PHP Designer 8, HTML, and CSS. The outcome of the research was the development of a Software as a Service Inventory Management System web application for Caterpro Ltd, with functions and scripts in order to give the required functionality to the web and meet the predefined requirements set from the company. The work was not built with intelligence. 


\section{METHODOLOGY}

The Demand and supply at a given time has a great impact on the level of stock at time ( $t$ ). A mathematical model for reordering is presented as

$(t)=(t)-D_{i}(t)+G_{i}(t)$

such that $Y_{i}(t) \geq Z$, where $i=1,2 \ldots n ., \quad Y_{i}(t)$ is the Net stock at warehouse $i$ at time $(\mathrm{t}), S_{i}(t)$ is the quantity in stock at warehouse $i$ at time $(\mathrm{t}), D_{i}(t)$ is the quantity of demand at warehouse $i$ at time (t) that is, the rate of depletion of stock at warehouse $i$ at time $(\mathrm{t}),(t)$ is the goods supply into the warehouse $i$ at time $(\mathrm{t})$, and is the threshold of the net stock. Due to the distributed nature of the inventories, the demand at the different point will not be the same, assuming that stock and demand can never be zero (0).

Knowledge representation is used for the intelligent system

Fuzzification: The fuzzy set $\mathrm{s} \in \mathrm{S}$ where $\mathrm{S}$ represents the universe of discuss for stock and the fuzzy set $d \in D$ where D represents the universe of discuss for demand consists of an element denoted by $\mathrm{x}$, given by

$s=\left\{\left(x, \mu_{s}(x)\right) \mid x \in \mathrm{S}, \mu_{s}(x) \in[0,1]\right\}$

$d=\left\{\left(x, \mu_{d}(x)\right) \mid x \in \mathrm{D}, \mu_{d}(x) \in[0,1]\right\}$

where $\mu_{s}(x)$ and $\mu_{d}(x)$ denote the membership function of $\mathrm{x}$ in $\mathrm{s}$ and $\mathrm{d}$ and $\mu_{s}$ and $\mu_{d}$ are the degrees of membership of $x$ in $\mathrm{s}$ and $\mathrm{d}$ in an interval of $[0,1]$.

Fuzzy Inference Engine: The above Fuzzy set employs the trapezoidal membership function

$f(x: a, b, c, d)=\left\{\max \left(\min \frac{x-a}{b-a}, 1, \frac{d-x}{d-c}\right), 0\right\}$

where $a$ is the minimum and $d$ is the maximum of the linguistic parameters, $\mathrm{b}$ and $\mathrm{c}$ are the core values of the linguistic variable $x$ that bounds its shape such that $\quad a \leq x \leq b$. Each of these parameters is described with the following linguistic terms: Very Low, Low, Average, High and Very High. In this work Mamdani type fuzzy inference is adopted for the design of the intelligent system
DeFuzzification: To decide the optimal order level, a crisp value is needed and to achieve an exact value, the centre-of-gravity method used is given as:

$C O G=\frac{\sum \mu_{R\left(X_{i}\right) X_{i}}}{\sum \mu_{R\left(X_{i}\right)}}$

where $\mu_{R}\left(x_{i}\right)$ is the membership function of $x_{i}$ in $\mathrm{R}$ and $x_{i}$ is the centre of membership function. Implementation of the proposed system is on a distributed systems based on client - server inventory application with all the stores ranging from $1, \ldots n$, where $\mathrm{n}$ is the maximum numbers of nodes connected to the server communicating using Java Remote Method Invocation (RMI) with a secure socket layer(SSL), other tools used for the proposed system are, My Structured Query Language (MySQL) Database Management System, Hypertext Markup Language (HTML), JavaScript, Hypertext Preprocessor (PHP) and Xampp (Apache).

\section{SYSTEM DESIGN}

The design of the Intelligent Inventory Management System is presented as follow

\subsection{SYSTEM ARCHITECTURE}

The architecture of the Web Based Intelligent Inventory Management System is presented in figure 1. The following are the components of the architecture:

a. The Client and Server Interface

i. Input Module

ii. Output Module

b. Web Services

c. Database

d. The Intelligent System

i. Fuzzy Inference System

ii. Fuzzification

iii. Inference Engine

iv. Rule base

v. Defuzzification 


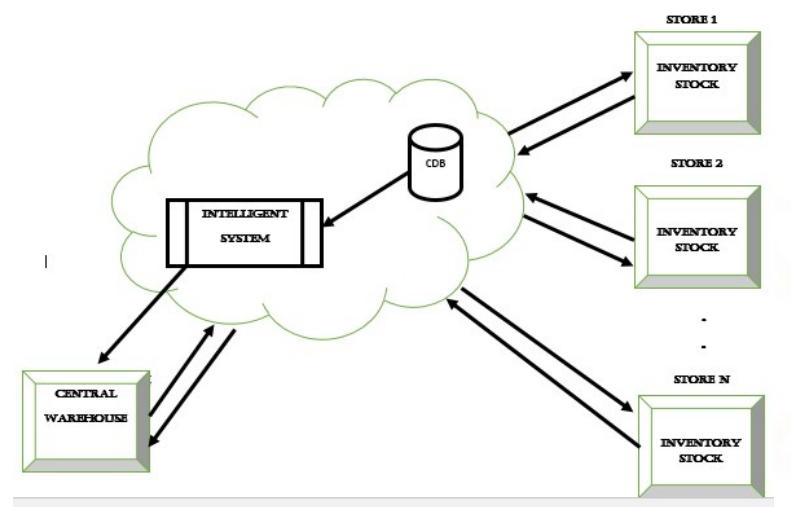

Fig 1. Hardware Architecture of the Web-Based Intelligent Inventory Management

\subsubsection{Client and Server Interface}

The architecture starts with a User Interface at both the Client and server side of the system which provides a means of entering all new supply and demands / sales into the inventory system through its Input Module. Client side of the system are the multiple stores of the organisation interconnected to the server, while the Server side is the head office of the organisation where central coordination takes place. The input module provides a user login where different level of authorization determine what privilege each users has to the system. The User Interface also provides an Output Module which enables users to view and monitor sales activity at the client and server side of the distributed system.

\subsubsection{Web Services}

The web services enables the deployment of a centralized database which enhances the management of sales at stores connected to the central server. This provides a means via which central inventory manager could communicate with employees remotely in order to elicit intelligent information from the client stores, the Intelligent Inventory Management System is a real-time inventory system designed using client - server model capable of connecting multiple stores. This is used to track the inventory of a single store, or to manage the distribution of stock between several branches of a larger organisations. However, the system record sales and restocking data and provides notification of low stock at any location through graphical and table representation, email and sms at a specified interval, the goal is to reduce the strain of tracking rather than to handle all store maintenance. Further features include the ability to generate reports of sales, but again the interpretation of the intelligent information is left to the inventory managers. In addition, since theft does occasionally occur, the system provides solutions for confirming the store inventory and for correcting stock quantities.

\subsubsection{Database}

The database used in this work represents a repository where record of acquired goods, record of sales transactions and the status of remaining stocks are stored.

\subsubsection{Intelligent System}

An intelligent system is a computer-based system that can represent, reason about, and interpret data. In doing so it can learn about the structure of the data, analyse the data to extract patterns and meaning, derive new information, and identify strategies and behaviour to act on the results of its analysis (Geoffrey, 2008). Requirements for an intelligent system include security, connectivity, the ability to adapt according to current data and the capacity for remote monitoring and management, the approach employed in the work for designing the intelligent system is fuzzy logic.

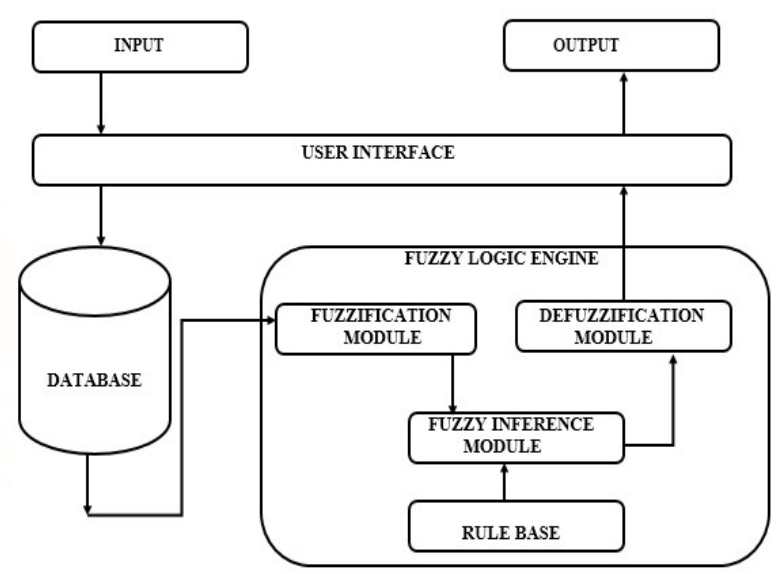

Fig. 2 Intelligent System Architecture 


\subsubsection{Fuzzification Process}

The system is designed to take demand and supply as input for decision variables from the client databases that would be used to determine the different re-order threshold points of all goods at the different stores with respect to sales made. In the process of fuzzification, a set containing all possible variables were considered while managing inventories. Then, membership functions are defined on the input variables and as well applied to their actual values so that the degree of truth for each rule premise can be determined.

\section{The Membership function for "STOCK" and}

\section{"DEMAND"}

Very Low $=\left\{\begin{array}{l}11 \leq x<50 \\ \frac{x-50}{150} 50 \leq x<200 \\ 0200 \leq x\end{array}\right.$

\section{Low}

$$
\left\{\begin{array}{cc}
\mathbf{0} & x<180 \\
\frac{x-180}{70} & 180 \leq x<250 \\
1 & 250 \leq x<320 \\
\frac{x-320}{80} & 320 \leq x<400 \\
0 \quad 400 \leq x
\end{array}\right.
$$

$$
\text { Average }=\left\{\begin{array}{cc}
0 & x<380 \\
\frac{x-380}{40} 380 \leq x<420 \\
\frac{1}{420} \leq x<450 \\
\frac{x-450}{150} 450 \leq x<600 \\
0 & 600 \leq x
\end{array}\right.
$$

$$
\text { High }=\left\{\begin{array}{cc}
0 & x<580 \\
\frac{x-580}{65} 580 \leq x<645 \\
1 \quad 645 \leq x<750 \\
\frac{x-750}{50} 750 \leq x<800 \\
0 \quad 800 \leq x
\end{array}\right.
$$

Very High $=\left\{\begin{array}{c}0 \quad x<780 \\ \frac{x-780}{70} 780 \leq x<850 \\ 1850 \leq x<1000\end{array}\right.$

\subsubsection{Fuzzy Inference Engine}

The Fuzzy Inference component of the intelligent system combines all the fired rules when determining the inventory level thresholds of the distributed points. The membership functions of all rule previously computed are combined into a single fuzzy set. The input of the aggregation process is the $=$ list of computed membership functions, and the output is a single value that is contained in the output fuzzy set. The Aggregation process (AGG) is done by the Inference Engine component which is driven by equation (11).

$$
\begin{aligned}
& A G G \\
& =\sum_{j=1}^{n} R_{j}^{2}
\end{aligned}
$$

Where $\boldsymbol{R}_{\boldsymbol{j}}$ represents a fired rule and $\mathrm{j}=1$, n; while $\mathrm{n}$ represents the number of fired rules when determining the threshold level of goods at the distributed points.

\subsubsection{The Rule Base}

Since there are two input variables (Stock and Sales) and five fuzzy sets for each fuzzy variables, the maximum possible number of rules in the rule base 
for fuzzy logic is $5^{2}=25$. The fuzzy rule base contains IF-THEN rules such as:

RULE 1: IF stock is very_high AND sales is very_high THEN reorder level is very_high; RULE 2: IF stock is high AND sales is very_high THEN reorderlevel is very_high;

RULE 3: IF stock is average AND sales is very_high THEN reorderlevel is very_high; RULE 4: IF stock is low AND sales is very_high THEN reorderlevel is very_high;

RULE 5: IF stock is very_low AND sales is very_high THEN reorderlevel is very_high; RULE 6: IF stock is very_high AND sales is high THEN reorderlevel is high;

RULE 7: IF stock is high AND sales is high THEN reorderlevel is high;

RULE 8: IF stock is average AND sales is high THEN reorderlevel is high;

RULE 9: IF stock is low AND sales is high THEN reorderlevel is very_high;

RULE 10: IF stock is very_low AND sales is high THEN reorderlevel is very_high; RULE 11: IF stock is very_high AND sales is average THEN reorderlevel is average; RULE 12: IF stock is high AND sales is average

THEN reorderlevel is average;

RULE 13: IF stock is average AND sales is average THEN reorderlevel is average; RULE 14: IF stock is low AND sales is average THEN reorderlevel is high;

RULE 15: IF stock is very_low AND sales is average THEN reorderlevel is high; RULE 16: IF stock is very_high AND sales is low THEN reorderlevel is very_low;

RULE 17: IF stock is high AND sales is low THEN reorderlevel is average;

RULE 18: IF stock is average AND sales is low THEN reorderlevel is average;
RULE 19: IF stock is low AND sales is low THEN reorderlevel is high;

RULE 20: IF stock is very_low AND sales is low THEN reorderlevel is very_high; RULE 21: IF stock is very_high AND sales is very_low THEN reorderlevel is low; RULE 22: IF stock is high AND sales is very_low THEN reorderlevel is low;

RULE 23: IF stock is average AND sales is very_low THEN reorderlevel is high; RULE 24: IF stock is low AND sales is very_low THEN reorderlevel is high;

RULE 25: IF stock is very_low AND sales is very_low THEN reorderlevel is very_high

\subsubsection{Defuzzification}

The Defuzzification process represents the last stage of the fuzzy inference system. Fuzziness helps us to evaluate the rules better, but the final output of a fuzzy system is converted to a crisp value since crisp values are easily interpreted and aid efficient decision making. The input to the defuzzification process is the aggregate fuzzy output gotten from equation (12). There are several defuzzification methods, but the most popular amongst them is the Centre of Gravity (COG) technique and it is adopted by this research. The $\boldsymbol{C O G}$ is expressed mathematically as:

$\operatorname{COG}=\frac{\int_{a}^{b} \mu X\left(X_{i}\right) X_{i} d X_{i}}{\int_{a}^{b} \mu X\left(X_{i}\right) d X_{i}}$

where $\mu_{X}\left(X_{i}\right)$ represents the membership value of $\boldsymbol{X}_{\boldsymbol{i}}$ and $\boldsymbol{X}_{\boldsymbol{i}}$ is the center of the membership function, while $\boldsymbol{a}$ and $\boldsymbol{b}$ represent the interval over which the integral is meant to take place.

\section{SYSTEM IMPLEMENTATION}

This describes the implementation of the intelligent inventory management system where software design is translated into source code. Each component is implemented as program module which is tested individually to determine if the modules are working as expected. This work is developed as a web - based application using php, Java, MySQL and HTML. 


\subsection{Login Page}

The login page is the main application interface that gives access or permission to client and server side of the system. The login page gives permission to other pages if only the correct email and corresponding password are provided. The login provides different level of access authorization into the system which determined to what privilege each user has to the system, the application checks if the email and the corresponding password provided is that of Level 0 or Level 1 or Level 2, this will determine the kind of page to be displayed.

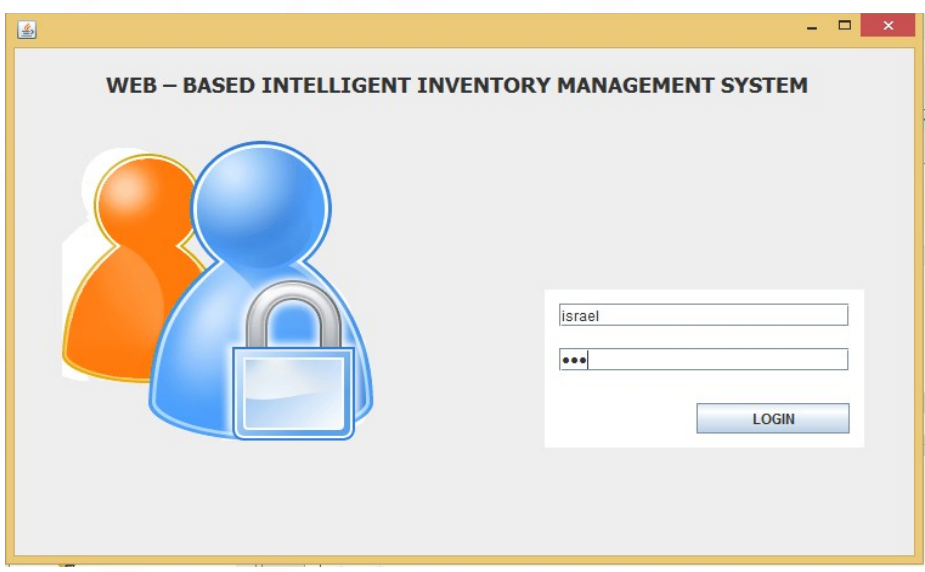

Fig. 3 Login page

\subsection{Central Dashboard}

This page provides access to all the client stores that are connected to the server in the distributed system, the level 0 admin can manage and monitor sales that are done at each stores by clicking on the icon of each client stores either to add, update, view or delete, level 0 also grant access to inventory head and sales person of any new client store

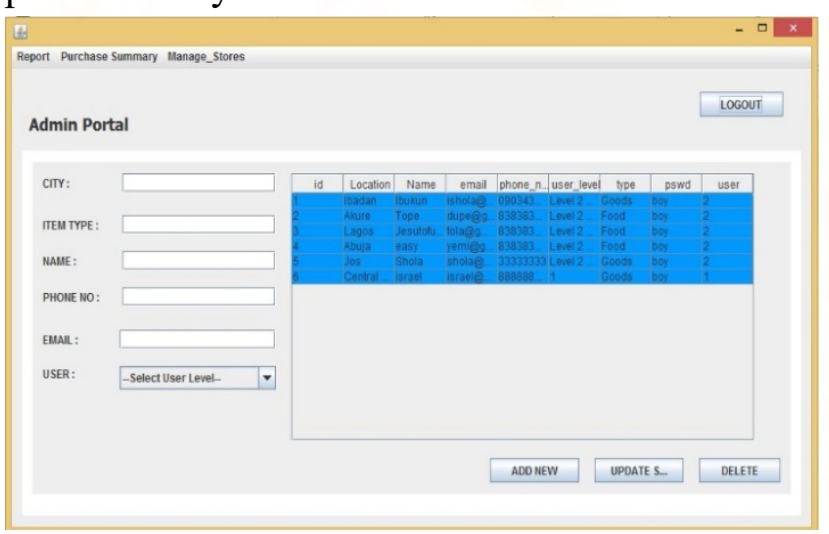

Fig 4. The Central Dashboard

\subsection{Store Access}

In this page of system the user-level 0 at the server side manages the allocation of access to the client stores describing which part of the store the user can have access to.

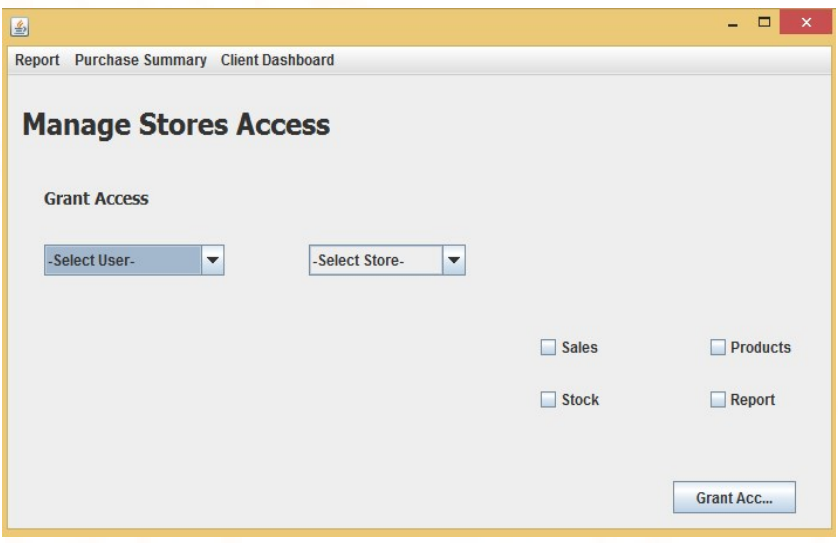

Fig.5 Store Access

\subsection{Client Dashboard}

This page contains a client stores that is connected to the server in the distributed system, the user level 1 and 2 can navigate depending on the access granted.

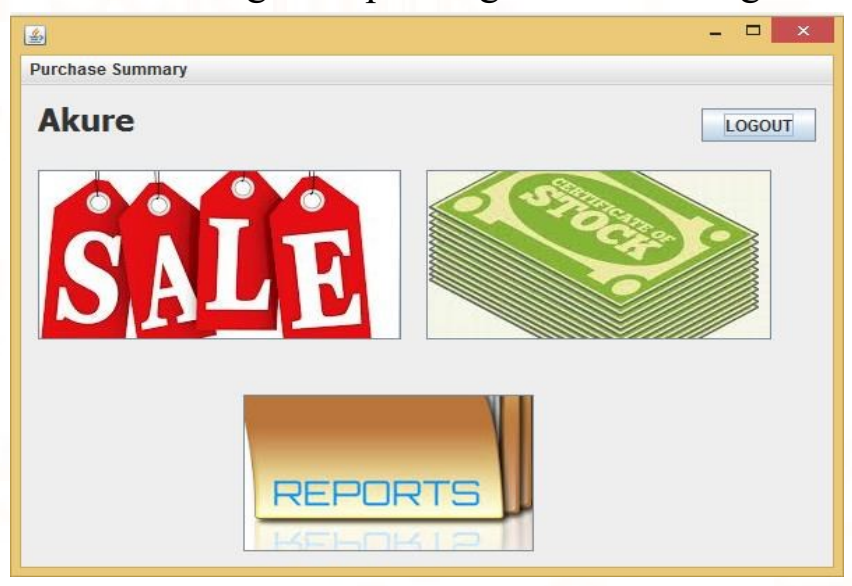

Fig. 6 Client Dashboard

\subsection{New Purchases}

This page captures news supply of goods into the each of client stores that are in the distributed system 


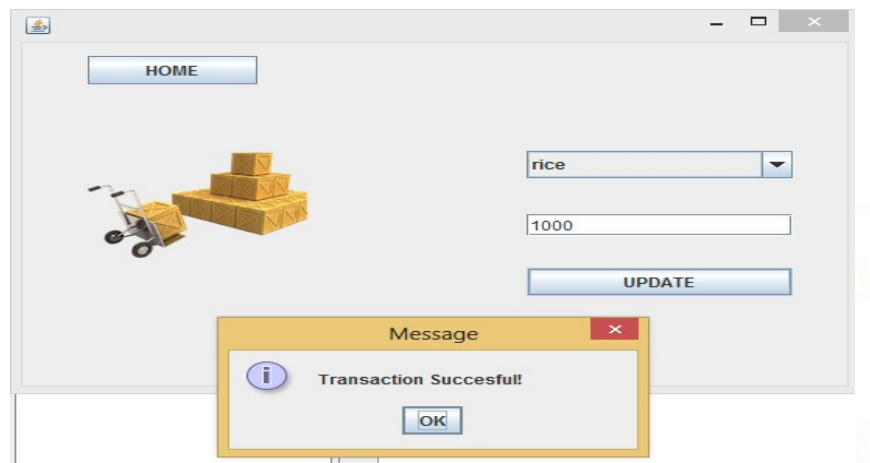

Fig. 7 New Purchases

\subsection{New Sales}

This page captures sales of goods out of each of client stores that is in the distributed system

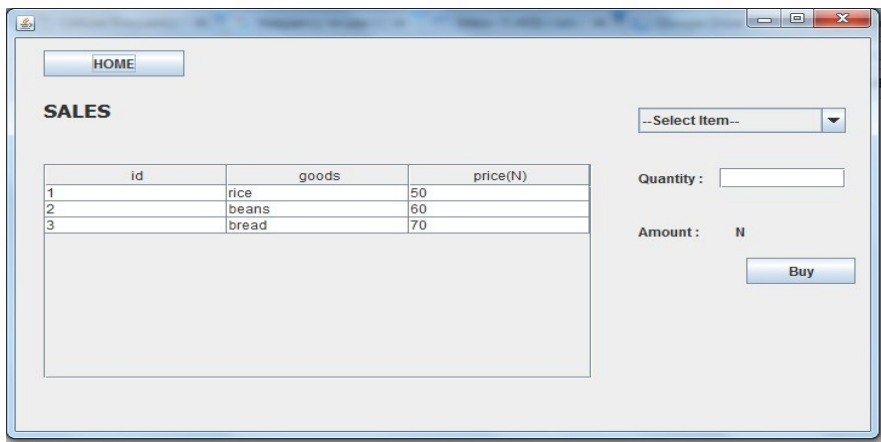

Fig. 8 New Sales

\subsection{Fuzzification and Defuzzification}

The Page captures the intelligent process of the system i.e. the fuzzification and the defuzzification of the inventory stores in the client - server system.

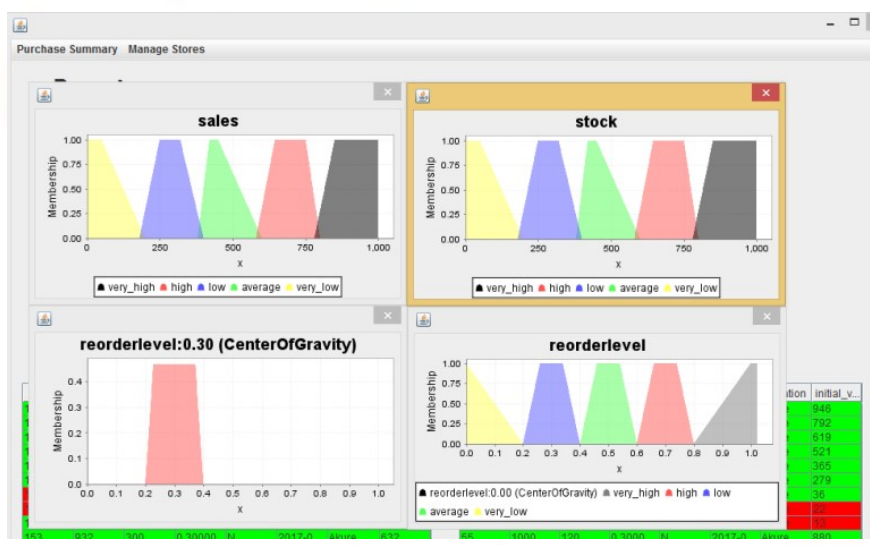

Fig. 9 Fuzzification and Defuzzification

\subsection{Results of Analysis}

The result of analysis in this work are the intelligent reporting of the sales activities and re-order levels in tables and graphs at the various client store that are in the distributed systems.

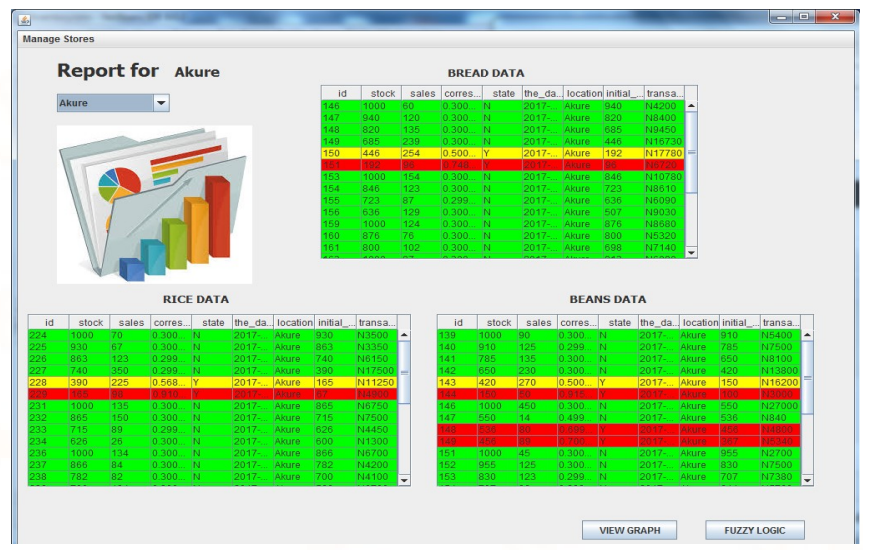

Figure 10 Summarization of Goods Sold at Store 1

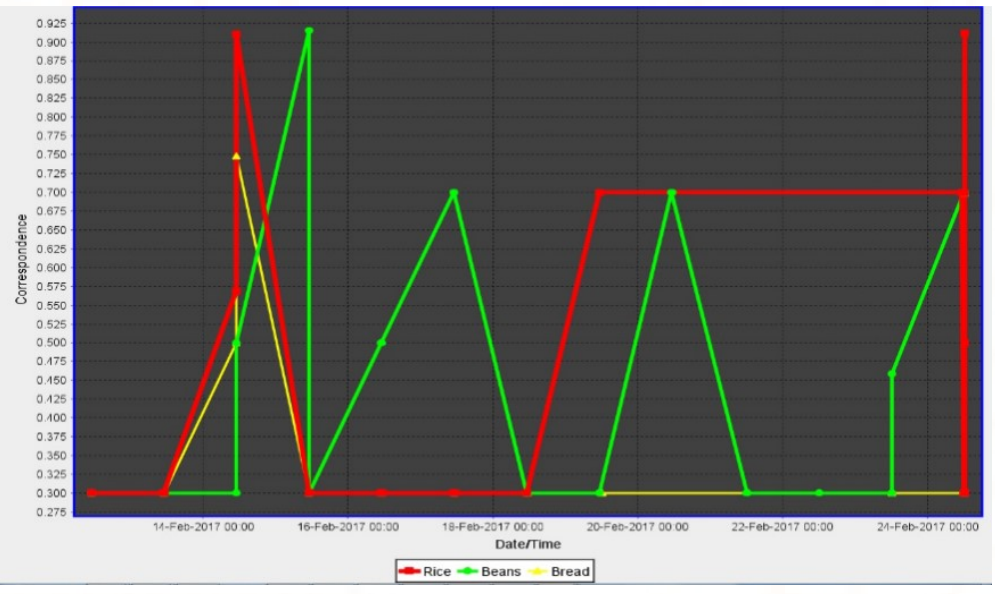

Fig. 11 Graph Reporting of Store 1 Inventory Reorder Level

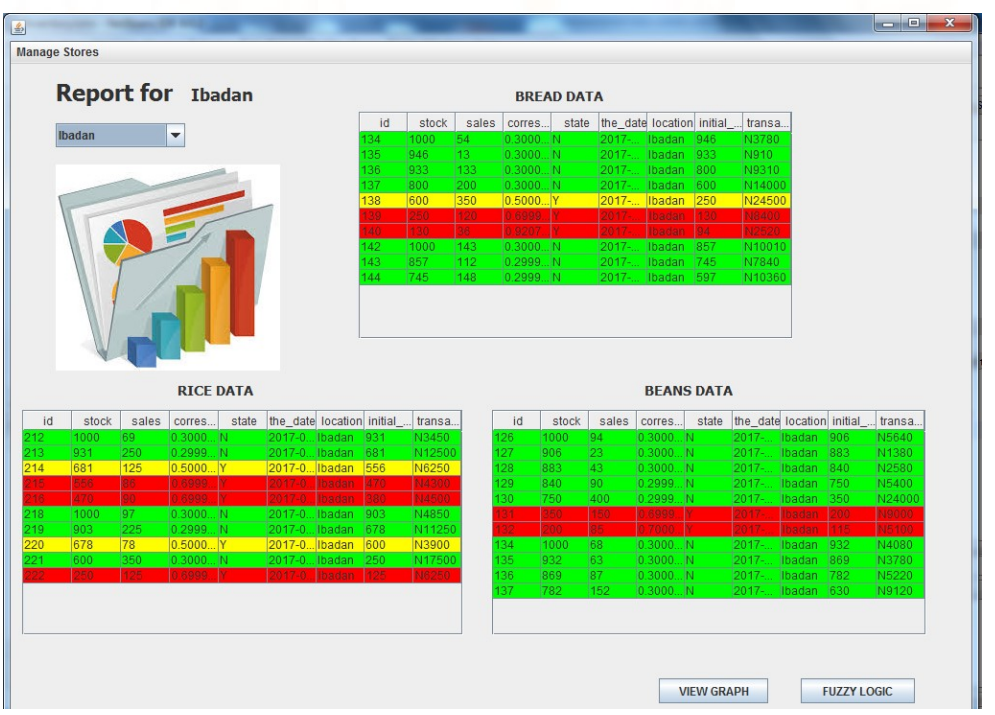

Fig. 12 Summarization of Goods Sold at Store 2 


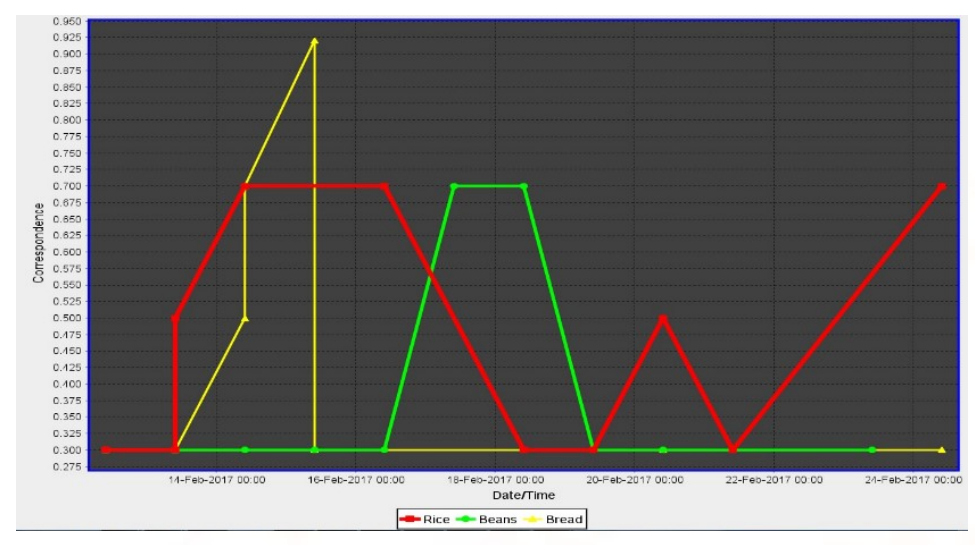

Figure 4.13: Graph Reporting of Store 2 Inventory Re-order Level

\section{CONCLUSION}

The intelligent system design in this work employs fuzzy logic approach to fuzzify supply and demand which serve as main inputs to the system to provide an intelligent reporting of information needed to make decisions for inventory managers. This is implemented in a distributed manner utilizing client - server model of architecture in a web - based environment. This system provides real time inventory monitoring of an organisation with multiple warehouses of locations for business operations.

\section{REFERENCES}

Abisoye O.A., Boboye, F. and Abisoye B.O., (2013) Design of A Computerized Inventory Management System for Supermarkets.

International Journal of Science and Research, Indian Online ISSN: 2319 - 7064 Volume 2 Issue III.

Addison W (2000), Fundamentals of Database Systems Longman, Inc. Elmasri/Navathe, Third Edition. Pp 7.

Anigbogu S. O., Oladipo O.F and Karim U (2011), An Intelligent Model for Sales and Inventory Management Indian Journal of Computer Science And Engineering ISSN: 0976-5166 Vol. 2 No. 5.
Anurag R, Ajinkya K, Anindya G and Mayuresh A (2013), Cloud Based Apartment Management System International Journal of Scientific \& Engineering Research, Volume 4, Issue 5 ISSN 2229-5518.

Ballou R H. (2004), Business Logistics/Supply Chain Management, Planning, Organising and Controlling the Supply Chain.5th Edition. PEARSON-Prentice Hall. USA. Pp 220 - 222

Bloomberg D.J, Lemay S and Hanna J B. (2002), Principles of Logistics. Prentice Hall. New Jersey. USA.

Bramer, M. A. (1988), Expert Systems in Business: A British Perspective. Expert Systems, Vol. 5, No. 2, pp. 104-117.

Ceng Liming and Han Ruizhu (2010), Simulation of distributed inventory management system, Computer Integrated Manufacturing Systems, 1006-5911 051067-07.

Chase R B, Jacobs F R and Aquilano N J. (2004), Operations Management for Competitive Advantage. 10th Edition. International Edition. MC GRAW HILL. NY.

Choo W. O., Chua S. C, Chue W. Y. and Lee L. H. (2013), Development of Simplified Inventory System with Online Synchronize Capability Journal of Science and Engineering Vol. 5 (1), 01-10.

David J. V. (1996), Basis of Inventory Management, Axzo Press $6^{\text {th }}$ Ed, Pp 95 - 97.

Fawcett, S.E., Ellram, L.M. and Ogden, J.A., (2007), Supply Chain Management: From Vision to Implementation. Pearson Education, Inc. New Jersey. Pp $126-128$

Fleming, I. (1992),"Stock Control or Insight", Prentice Hall New York, Pp 9 - 11 
Fu Y, Xu T and Wang H. D. (2013), Building Intelligent Agent oriented modelling of complex distributed systems, Journal of Beijing University of Technology, 20110254, 0037: 06 - $0955-6$

Geoffrey S (2008), Introduction to Computer Information Systems. Kendall Hunt Publishing Company USA. Pp $82-83$

Godwin U. (1993): "The Impact of Telecommunications on Inventory Management." Production and Inventory Management Journal. Volume IV (ISSN: 1151-4016)

Hosseini, J., Baharaeen S., and Zheng X. T. Spring (1988), Design of a Knowledge- Based System for Inventory Control. Journal of Engineering Computing and Application, pp. 28-35.

Karim A.M, Mohd F. S. and Mahbubul H. (2011), Development Of A Prospective Web-Based Inventory System For Management Of Lab Facilities Journal Of Emerging Trends In Engineering And Applied Sciences (JETEAS) 2 (1): 36-42 (ISSN: 2141-7016)

Kazuo T and Hua O. W (2001),Fuzzy control systems design and analysis: a linear matrix inequality approach. John Wiley and Sons.ISBN978-0-47132324-2.

Khanlarpour E., Fazlollahtabar H. and Mahdavi I., (2013), Designing An Intelligent Ware House Based On Genetic Algorithm And Fuzzy Logic For Determining Reorder Point And Order Quantity. Journal of Computer Science and Information Technology Vol. III (ISSN: 23415016)

Loizides A (2013), Development of a SaaS Inventory Management System, A thesis Submitted to the Department of Business Information Technology, Kemi -Tornio University of Applied Science, Tornio.

Luxhoj, J. T., Agnihotri, D., Kazunas, S., and Nambiar, S. (1993), A Proposed KnowledgeBased System (KBS) for Selection of Inventory Control
Policies. International Journal of Production Research, Vol. 31, No. 7, pp. 17091720.

Martin K. S and David W. M (1986), "Inventory Control Theory and Practice" Prentice - Hall New Jersey, India.

Parlar, M. (1989), EXPIM: A Knowledge-Based Expert System for Production/Inventory Modelling. International Journal of Production Research, Vol. 27, No. 1, pp. 101-118.

Simon, H.A., (1981), "The Science of the Artificial", MIT Press. $2^{\text {nd }}$ Edition. ISBN 0262193744 Pp 91 - 93

Tanthatemee T., Phruksaphanrat B. (2012), Fuzzy Inventory Control System for Uncertain Demand and Supply. International Association of Engineers Volume 7 Pp.1224-1229

Waters, C.D.J., (2003), Inventory Control and Management - 2nd Edition. John Wiley \& Sons Ltd Chichester. Pp $56-60$

Youakin B., Richard C., Ajith A and Aboul - Ella H (2010) Emerging Web Intelligence: Advance semantic technology. Springer London Dordrecht Heidelberg New York. ISSN 1610 - 3947 ISBBN 978-1-84996-076-2. Pp. 358 - 362. 